\title{
Review
}

\section{Helminth Modulation of Lung Inflammation}

\author{
Christian Schwartz, ${ }^{1, *}$ Emily Hams, ${ }^{1}$ and Padraic G. Fallon ${ }^{1, *}$
}

Parasitic helminths must establish chronic infections to complete their life cycle and therefore are potent modulators of multiple facets of host physiology. Parasitic helminths have coevolved with humans to become arguably master selectors of our immune system, whereby they have impacted on the selection of genes with beneficial mutations for both host and parasite. While helminth infections of humans are a significant health burden, studies have shown that helminths or helminth products can alter susceptibility to unrelated infectious or inflammatory diseases. This has generated interest in the use of helminth infections or molecules as therapeutics. In this review, we focus on the impact of helminth infections on pulmonary immunity, especially with regard to homeostatic lung function, pulmonary viral and bacterial (co)infections, and asthma.

\section{Helminth Infections Influence the Lung Environment}

The fascinating life cycles of helminths can include multiple intermediary hosts, different routes of entry into the human body, and migration within the host from the point of entry to the location where sexual propagation of the worm's life cycle takes place. These migratory routes depend on the helminth species and may lead them through the lung, either as a developmental step or simply to transit from within the body (tissue, blood vessels) to the luminal space of the lung or intestine. The life cycles of a range of helminth species involve the migration of developing larvae through the lung of the infected host, as well as entry of adult worms or the deposition of eggs into the lungs, all of which cause pulmonary tissue damage and pathology (Table 1). A paradox is why certain helminths that reside in the intestine or other tissue sites as adults have evolved to need a lung migration phase as part of their life cycle [1].

Here, we summarise recent data on the interplay of helminths and the pulmonary immune response, review recent literature on novel helminth-derived immunomodulators that might be useful as therapeutics, and highlight the impact helminths have on bacterial and viral coinfections.

\section{Helminth Infections Induce Damage to the Lung}

The migration of the larvae of helminths such as Schistosoma mansoni, Ascaris lumbricoides, and hookworms (Necator americanus or Ancylostoma duodenale) through the lung has been particularly well investigated. Pulmonary damage caused by helminths leads to the development of a type 2 immune response (Figure 1), which is associated with wound healing, with active immunomodulation by the parasite leading to long-term changes in lung function.

There are several ways through which helminths influence pulmonary immunity - either by direct damage caused by migration, the dissemination of eggs, or the release of immunomodulators - all of which alter normal pulmonary function and modify responses against further insults.

Migrating Larvae Inflict Damage and Induce Wound Healing in the Lung

While the migrating larvae of hookworms cause mechanical and enzymatic damage to the lung parenchyma and epithelium, with patients presenting with coughing, wheezing, and
Highlights

Helminths influence the lung immune response by direct damage, active immunomodulation, and initiation of regulatory mechanisms. Differences exist when worms modulate pulmonary responses systemically or alter responses as a consequence of damage responses.

Migration of larvae through the lung triggers a wound-healing response.

Helminths introduce immunoregulation into Th2 responses, a quality which is not present in allergic responses.

Helminths and their immunomodulatory molecules ameliorate lung inflammation, including asthma.

Helminth coinfections impair responses against viral and (myco-) bacterial pulmonary infection.

${ }^{1}$ School of Medicine, Trinity Biomedical Sciences Institute, Trinity College Dublin, Dublin 2, Ireland

${ }^{*}$ Correspondence:

christian.schwartz@tcd.ie (C. Schwartz) and pfallon@tcd.ie (P.G. Fallon). 
eosinophilic pneumonia (Löffler's syndrome, see Glossary), there is remarkable repair of pulmonary pathology postmigration. Experimental studies with the rodent hookworm Nippostrongylus brasiliensis have led to many discoveries, not only on helminth-induced lung damage and repair, but also aiding fundamental insights into immune function. The importance of the modulation of pulmonary immunity during hookworm infection is evident from recent studies demonstrating a link between innate immune cellular responses and signals derived from the central nervous system (CNS). This is demonstrable by the discovery of group 2 innate lymphoid cells (ILC2) in N. brasiliensis-infected mice [2-4]. ILC2s express the receptor for the neuropeptide neuromedin $U$ (NMUR), with NMU signaling (through the NMUR) integrating CNS-derived signals with immunity to mount a robust innate antiparasite type 2 pulmonary response in the lungs of hookworm-infected mice [5-7]. Indeed, another critical cell type in the immune response against hookworms is the Tuft cell, which contributes to expel the worms from the intestine using a feed-forward loop: Tuft cells can sense the presence of helminths via chemosensory receptors, leading to the release of interleukin (IL)-25, which activates intestinal ILC2s. ILC2s then release IL-13, thereby promoting both Tuft cell and goblet cell hyperplasia [8-10]. In the lungs, a phenotypically similar cell type to the intestinal Tuft cell - the brush cell - is present and may exert similar functions in the genesis of pulmonary type 2 immunity [11], although this has not been formally addressed to our knowledge.

A hallmark of worm-induced lung damage is long-term alteration in the structure of the lung. IL-13 release during infection leads to type 2 macrophage (M2) polarization of resident and recruited mononuclear cells, which persists for months after the adult worms are expelled from the intestines [12]. During experimental hookworm infection, neutrophils and monocytes are quickly recruited to the damaged lung. The release of the chitinase-like protein $\mathrm{Ym} 1$ from M2-polarised macrophages promotes the mobilisation and recruitment of neutrophils to the lung, and an early increase in IL17A from $\gamma \boldsymbol{\delta} \mathbf{T}$ cells further contributes to helminth-induced pulmonary damage [13]. Additionally, progressive lung destruction can be observed long after infection, as evidenced by long-lasting emphysema-like lesions in the lungs of previously infected mice [12]. Interestingly, although hookworm-infected mice show an increase in transcripts of both CD4 T helper (Th)1- and Th2-associated cytokines in the lung, allergen sensitization and challenge results in a decrease in allergen-specific Th2 responses and reduced inflammation [14]. It has further been reported that Th1 and Th17 cells can be converted to IL-4-expressing Th2 cells [15] and, using fate reporter mice, it has been shown that Th17 cells induced during primary infections with $N$. brasiliensis can be converted into regulatory $\mathrm{Tr} 1$ cells to prevent overt pulmonary inflammation during a subsequent encounter [16]. In summary, the intricate network of cellular interactions in response to larvae-inflicted damage changes the pulmonary cellular composition and acts to limit damage while allowing for efficient protective immunity [17].

\section{Dissemination of Eggs and Hyperinfection Severely Impair Lung Function}

In addition to damage caused by larval migration, damage to the lung can be caused by the unchecked dissemination of worms from other sites, as well as the deposition of eggs into the lung. Life-threatening pulmonary damage can be caused by hyperinfection with Strongyloides due to an autoinfectious cycle, which is mostly seen in immunocompromised individuals. Here, infective larvae penetrate the intestinal wall and enter the lung via the bloodstream, leading to oedema, dyspnoea, and pleural effusion (reviewed in [1]).

Although schistosomulae migrate through the lung, the main pulmonary pathology of Schistosoma infection manifests after eggs are deposited in the bloodstream and disseminated by the adult worms residing in the mesenteric venules. Because of their size and shape, the highly immunogenic eggs are lodged in the pulmonary blood vessels, transmigrate into the lung

\section{Glossary}

Anaphylaxis: life-threatening allergic reaction mediated predominately by IgE-bearing mast cells. Release of histamine and other mediators from mast cells leads to rashes, dyspnoea, vasodilation, vascular leakage, and a rapid drop in blood pressure.

Basophil granulocyte: circulating innate type 2-associated effector cell; it responds to IgE-cross-linking of the high-affinity $\mathrm{Fc}$ receptor for IgE with the release of IL-4.

BCG vaccine: vaccine against tuberculosis through injection of virulence-reduced (attenuated) live bovine tuberculosis pathogen Mycobacterium bovis.

CCR2/CX3CR1 ${ }^{+}$monocytes: the chemokine receptors that direct circulating monocytes towards sites of injury. C-C chemokine receptor 2 (CCR2) detects monocyte chemoattractant protein-1 (CCL2), CX3C chemokine receptor 1 (or fractalkine receptor) binds $\mathrm{CX} 3 \mathrm{CL} 1$ (or fractalkine).

CD: cluster of differentiation, identification system for cell-surface molecules.

Class switching: immunoglobulin class switch recombination to generate different classes of antibodies (isotypes) by exchanging the constant part of the heavy chain, thereby altering the function of the antibody while maintaining its antigenic specificity.

Damage-associated molecular patterns (DAMPs): host-derived molecules able to initiate an immune response. One subset are nuclear and cytosolic proteins that indicate damage when detected in the extracelluar space.

Dyspnoea: shortness of breath. Eosinophil granulocyte: innate type 2-associated effector cell releasing cytokines, peroxidase, and enzymes. Develops in response to IL-5, recruited by eotaxins.

Fate reporter mice: transgenic mice, which are engineered to express a unique marker, usually a fluorescent protein, together with the protein of interest to allow for tracking of the protein-expressing cells.

$\gamma \delta \mathbf{T}$ cells: $T$ cell expressing the $\gamma \delta$ $T$ cell receptor (instead of the more abundant $\alpha \beta$ T cell receptor T cells), 
parenchyma, and are encapsulated by a type 2 granuloma. The initial granuloma consists of mainly T cells and eosinophils [18]. The composition of the granuloma changes over time with the accumulation of collagen-depositing M2 macrophages becoming more and more fibrotic, leading to pulmonary hypertension [18].

The necessity of a functional Th2 response becomes evident in Schistosoma infections where the initial Th1 response switches towards a Th2 response after deposition of Schistosoma eggs [19]. Mice incapable of mounting a Th2 response are unable to facilitate egg transition and initiate wound repair processes, and so succumb to the infection [20,21]. Similarly, mice with impaired Th2 induction (IL-4R $\alpha^{-/-}$) or effector cytokines (IL-4 $4^{-/-} \mathrm{IL}-5^{-/-} \mathrm{IL}-9^{-/-} \mathrm{IL}-13^{-/-}$) are unable to expel $N$. brasiliensis due to the lack of a functional Th2 response [22,23]. However, during chronic stages of Schistosoma infection, regulatory $T$ and B cells limit the Th2 response to prevent immunopathology [24,25].

Release of Helminth-Derived Immunomodulators Regulates Pulmonary Inflammation Although Brugia malayi microfilariae only circulate in the blood of their human hosts, they can alter immune responses in the lungs. Adaptation of $B$. malayi to its host and vector (mosquito) has led to a synchronised circadian rhythm, whereby the microfilariae are present in the blood when the mosquito feeds; at other times they are sequestered to the lung capillaries [26]. Continuous presence of the microfilariae within the pulmonary circulation requires the downregulation of the immune response by helminth-secreted immunomodulatory molecules, mainly targeting eosinophils, which are required for protection from B. malayi. Limiting eosinophil responses within the lung has a concomitant beneficial effect on allergic airway responses, during which eosinophils are the main effector cells eliciting inflammation [27].

Most interesting are helminth species that are able to modulate pulmonary responses while never physically entering or residing in the lung. The gastrointestinal nematode Heligmosomoides polygyrus attenuates airway inflammation by directly releasing mediators in their excretory-secretory (ES) products, such as a transforming growth factor (TGF)- $\beta$ mimic, which induces regulatory $T$ cells (Tregs) in vitro and in vivo [28]. Another intriguing mechanism by which Tregs can be induced during helminth infection was revealed in a recent study showing that $H$. polygyrus modulates the caecal microbiome. Changes in the microbiome composition introduced by $H$. polygyrus infection increased the availability of microbial-derived short-chain fatty acids, which alters pulmonary Treg function via the cognate short-chain fatty acid receptor GPR41, thereby reducing lung inflammation [29].

As there is a body of data showing that the intestinal microbiota and its interaction with the gut epithelia shapes immune responses at distal sites, such as the lung, changes introduced by infection with gastrointestinal worms may also influence immune responses in the lung. A study conducted with Schistosoma haematobium-infected children observed significant changes in the composition of the faecal microbiome compared to uninfected children [30]. Praziquantel treatment to remove the worms did not alter the microbiome composition [30], arguing for longlasting changes of the intestinal microbiome imposed by the parasite. During schistosomiasis, egg translocation from the blood vessels through the intestinal epithelium into the lumen causes constant immunomodulation through disseminated bacteria. However, at the same time, regulatory macrophages - $\mathrm{T}$ and $\mathrm{B}$ cells induced during Schistosoma infection - prevent a cytokine storm and concomitantly protect against excessive lung inflammation [24,31-33]. It remains to be determined to what extent alterations of the microbiota influence the regulatory networks underlying schistosomiasis. While other helminths alter the microbiome composition or migrate from the intestine into the lung (Ascaris), it is unclear whether these changes
Enriched in epithelial and mucosal tissues.

Goblet cell: intestinal or bronchial cell population secreting mucins that form the mucous layer protecting the intestinal or airway epithelia.

Granuloma: accumulation of immune cells around a foreign substance within the tissue. Heterodimer: macromolecular complex consisting of two different macromolecules. Here: receptor made up of two different receptor proteins.

latrogenic: related to illness caused by medical treatment (here: the infection with a helminth as treatment).

Immunogenic: ability of an antigen or epitope (e.g., schistosome eggs) to evoke humoral and/or cellular immune responses.

Löffler's syndrome: acute onset pulmonary accumulation of eosinophils.

Macrophage polarization: lipopolysaccharide and interferon- $\gamma$ polarize classically activated macrophages (or M1) producing proinflammatory mediators.

Alternatively activated macrophages (or M2) by IL-4, IL-13, or IL-10, are associated with type 2 and wound healing responses.

Neutrophil granulocyte: circulating phagocytic innate cell associated with inflammation, releases peroxidase, proteases, defensins. Oedema: abnormal accumulation of fluids in tissue.

Pleural effusion: also 'pulmonary effusion', fluids leaking in the pleura space between lung and chest cavity.

Weep-and-sweep-reaction:

characteristic intestinal response to helminth infections, in which increased luminal fluid ('weep') and increased smooth muscle contractility 'sweep' out the helminth residing in the intestinal lumen. 


\section{Trends in Parasitology}

Table 1. Human Helminth Parasites That Influence Pulmonary Immune Responses ${ }^{a}$

\begin{tabular}{|c|c|c|c|c|c|c|}
\hline Helminth & Infection & Effect on lung & Migratory route & Life span & Mouse model & $\begin{array}{l}\text { Mode of lung } \\
\text { modulation }\end{array}$ \\
\hline \multicolumn{7}{|l|}{ Nematodes } \\
\hline $\begin{array}{l}\text { Ancylostoma } \\
\text { duodenale }\end{array}$ & L3, skin & Löffler syndrome & $\begin{array}{l}\text { Skin - blood - LUNG - } \\
\text { trachea - stomach - } \\
\text { small intestine }\end{array}$ & $1-2$ years & $\begin{array}{l}\text { Nippostrongylus } \\
\text { brasiliensis, } \\
\text { Heligmosomoides } \\
\text { polygyrus }\end{array}$ & $\mathrm{D}, \mathrm{IM}$ \\
\hline $\begin{array}{l}\text { Necator } \\
\text { americanus }\end{array}$ & L3, skin & Löffler syndrome & $\begin{array}{l}\text { Skin - blood - LUNG - } \\
\text { trachea - stomach - } \\
\text { small intestine }\end{array}$ & $3-5$ years & $\begin{array}{l}\text { Nippostrongylus } \\
\text { brasiliensis, } \\
\text { Heligmosomoides } \\
\text { polygyrus }\end{array}$ & $\mathrm{D}, \mathrm{IM}$ \\
\hline $\begin{array}{l}\text { Ascaris } \\
\text { lumbricoides }\end{array}$ & Eggs, oral & Löffler syndrome & $\begin{array}{l}\text { Small intestine - cecum - } \\
\text { liver - LUNG - trachea - } \\
\text { small intestine }\end{array}$ & $1-2$ years & Ascaris suum & $\mathrm{D}, \mathrm{IM}$ \\
\hline $\begin{array}{l}\text { Strongyloides } \\
\text { stercoralis }\end{array}$ & L3, skin/autoinfection & $\begin{array}{l}\text { Löffler syndrome, } \\
\text { eosinophilic pneumonia }\end{array}$ & $\begin{array}{l}\text { Skin - blood - LUNG - } \\
\text { trachea - small intestine }\end{array}$ & & Strongyloides ratti & $\mathrm{D}$ \\
\hline Brugia malayi & L3, vector & Pulmonary eosinophilia & $\begin{array}{l}\text { Skin - lymph; } \\
\text { microfilariae: blood }\end{array}$ & $5-15$ years & Brugia malayi & $\mathrm{IM}$ \\
\hline Loa loa & L3, vector & $\begin{array}{l}\text { Eosinophilic pleural } \\
\text { effusion }\end{array}$ & $\begin{array}{l}\text { Skin; microfilariae: blood, } \\
\text { spinal fluid, urine, LUNG }\end{array}$ & $<15$ years & - & $\mathrm{IM}$ \\
\hline Toxocara (Z) & Eggs, oral & Eosinophilic pneumonia & $\begin{array}{l}\text { Small intestine - LUNG, } \\
\text { liver, muscle, brain }\end{array}$ & - & Toxocara canis & $\mathrm{D}$ \\
\hline \multicolumn{7}{|l|}{ Trematodes } \\
\hline $\begin{array}{l}\text { Schistosoma } \\
\text { mansoni }\end{array}$ & Cercariae, skin & $\begin{array}{l}\text { Löffler syndrome, } \\
\text { granulomas }\end{array}$ & $\begin{array}{l}\text { Skin - blood - LUNG - } \\
\text { blood (mesentery) }\end{array}$ & $<30$ years & $\begin{array}{l}\text { Schistosoma } \\
\text { mansoni }\end{array}$ & $\mathrm{D}, \mathrm{G}, \mathrm{IM}$ \\
\hline $\begin{array}{l}\text { Schistosoma } \\
\text { hematobium }\end{array}$ & Cercariae, skin & $\begin{array}{l}\text { Löffler syndrome, } \\
\text { granulomas }\end{array}$ & $\begin{array}{l}\text { Skin - blood - LUNG - } \\
\text { blood (bladder) }\end{array}$ & $<30$ years & $\begin{array}{l}\text { Schistosoma } \\
\text { hematobium }\end{array}$ & $\mathrm{D}, \mathrm{G}, \mathrm{IM}$ \\
\hline $\begin{array}{l}\text { Schistosoma } \\
\text { japonicum }\end{array}$ & Cercariae, skin & $\begin{array}{l}\text { Löffler syndrome, } \\
\text { granulomas }\end{array}$ & $\begin{array}{l}\text { Skin - blood - LUNG - } \\
\text { blood (mesentery) }\end{array}$ & $<30$ years & $\begin{array}{l}\text { Schistosoma } \\
\text { japonicum }\end{array}$ & $\mathrm{D}, \mathrm{G}, \mathrm{IM}$ \\
\hline Paragonimus (Z) & Metacerc., oral & Cough, pleural lesions & Small intestine - LUNG & $<20$ years & & $\mathrm{D}, \mathrm{IM}$ \\
\hline \multicolumn{7}{|l|}{ Cestodes } \\
\hline $\begin{array}{l}\text { Echinococcus } \\
\text { granulosus }\end{array}$ & Eggs, oral & Cough, pleural lesions & $\begin{array}{l}\text { Small intestine - LUNG, } \\
\text { liver }\end{array}$ & - & $\begin{array}{l}\text { Echinococcus } \\
\text { granulosus }\end{array}$ & $\mathrm{IM}$ \\
\hline $\begin{array}{l}\text { Echinococcus } \\
\text { multilocularis }\end{array}$ & Eggs, oral & Cough, pleural lesions & $\begin{array}{l}\text { Small intestine - LUNG, } \\
\text { liver }\end{array}$ & - & & $\mathrm{IM}$ \\
\hline
\end{tabular}

aAbbreviations: (Z), zoonosis; D, damage; G, granuloma; IM, immunomodulatory molecules.

modulate pulmonary immune responses. Infections with Schistosoma and Heligmosomoides illustrate that the presence of the helminth within the lung is not required to influence pulmonary responses and rather the release of parasite-derived immunomodulatory molecules may have systemic effects, including influencing lung inflammation.

In conclusion, helminth-induced lung inflammation is initiated in distinctive processes that prompt a wound-healing response or directly act on mechanisms of wound healing.

\section{The Wound-Healing Response}

Migration of helminth larvae damages the lung epithelia, hence it is in both the host's and the helminth's interest to repair it and restore lung function (Figure 2). Typically, damage is induced in areas where larvae breach through the alveolar epithelia and destroy respiratory epithelial 


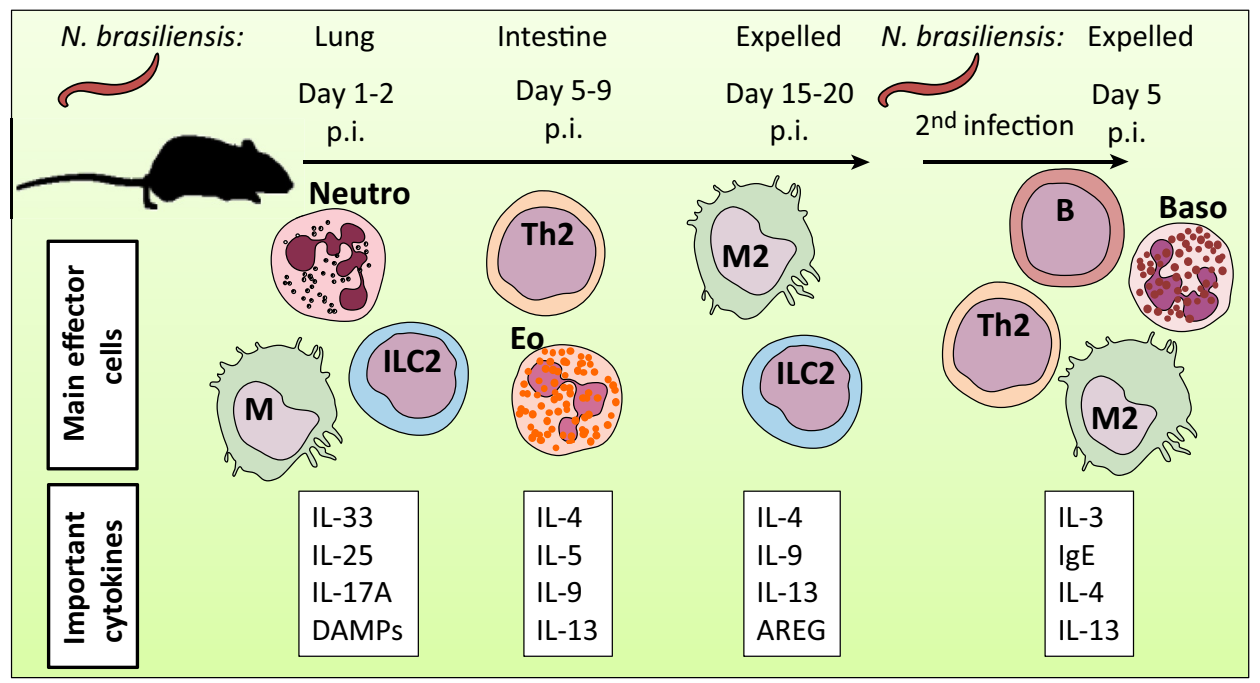

Trends in Parasitology

Figure 1. The Prototypical Type 2 Immune Response against Nippostrongylus brasiliensis. After Nippostrongylus larvae enter the skin of the host, they migrate within $24-48 \mathrm{~h}$ via the bloodstream to the lungs. Between days 2 and 3 post infection (p.i.), they breach through the alveoli and migrate to the intestine, where they reside, mate, and produce eggs (days 5-7) until they are expelled between days 7 and 12. In a subsequent infection, migrating larvae are killed between days 0 and 5 , and only a few worms reach the intestine. Type 2 immune responses are evoked through damage-induced and active release of large amounts of the alarmins interleukin (IL)-33 and IL-25, and other damageassociated molecular patterns (DAMPs) from epithelial cells and type II alveolar macrophages. The first responders to alarmins and helminth antigens are group 2 innate lymphoid cells (ILC2s) and dendritic cells (DCs). ILC2s release type 2 cytokines, such as IL-4, IL-5, IL-9, and IL-13, thereby promoting eosinophilia (Eo). MHC2-dependent activation of T cells in the lung draining lymph nodes and activation in the tissue requires a concerted action of DCs, ILC2s and other IL-4producing cell populations. ILC2s directly interact with CD4 T cells via MHC class II and costimulatory molecules - such as inducible costimulator, inducible costimulator-ligand and programmed death receptor ligand 1-and directly shape the differentiation of adaptive immunity [112-114]. Th2 cells are then instrumental in recruiting basophils to the lung and provide help to B cells to produce lgG1, IgG4, and IgE isotype-switched antibodies. While the immune response in the intestine develops and expels the parasite via a weep-and-sweep-reaction in an IL-13-dependent manner, in the lung tissue repair and remodelling are initiated. This process starts with the early release of IL-17A and the recruitment of neutrophils (Neutro) and monocytes to the site of damage. IL-4R $\alpha$-dependent alternative activation of macrophages (M2) initiates wound healing and tissue remodelling involving amphiregulin (AREG) and IL-9. During a second infection with $N$. brasiliensis, IgE-dependent activation of basophils (Baso) and their release of type 2 cytokines accelerates worm expulsion [103].

cells. This causes emphysema-like lesions, including formation of blood clots, and the release of damage-associated molecular patterns (DAMPs), such as chromatin-associated highmobility group box 1 (HMGB-1), extracellular DNA/RNA, or nucleotides, S100-proteins, and alarmins. Tissue-resident macrophages sense these DAMPs and induce a proinflammatory environment followed by the recruitment of circulating CCR2/CX3CR1 ${ }^{+}$monocytes (reviewed in [34]). The recruited monocytes differentiate into macrophages and assist resident macrophages with tissue formation: macrophage-derived growth factors induce differentiation and proliferation of cells and induce extracellular matrix deposition. Importantly, successful wound healing requires prevention of the influx of more proinflammatory cells [35]. Resolution of inflammation is achieved through the phagocytosis of apoptotic neutrophils, which acts as a trigger for macrophages to release the anti-inflammatory cytokines TGF- $\beta$ and IL-10, for the blockade of proinflammatory IL-1 signalling, and the release of arginase-1 (Arg-1) and amphiregulin (AREG), which reduce inflammation and promote tissue formation $[34,36]$. 


\section{Trends in Parasitology}

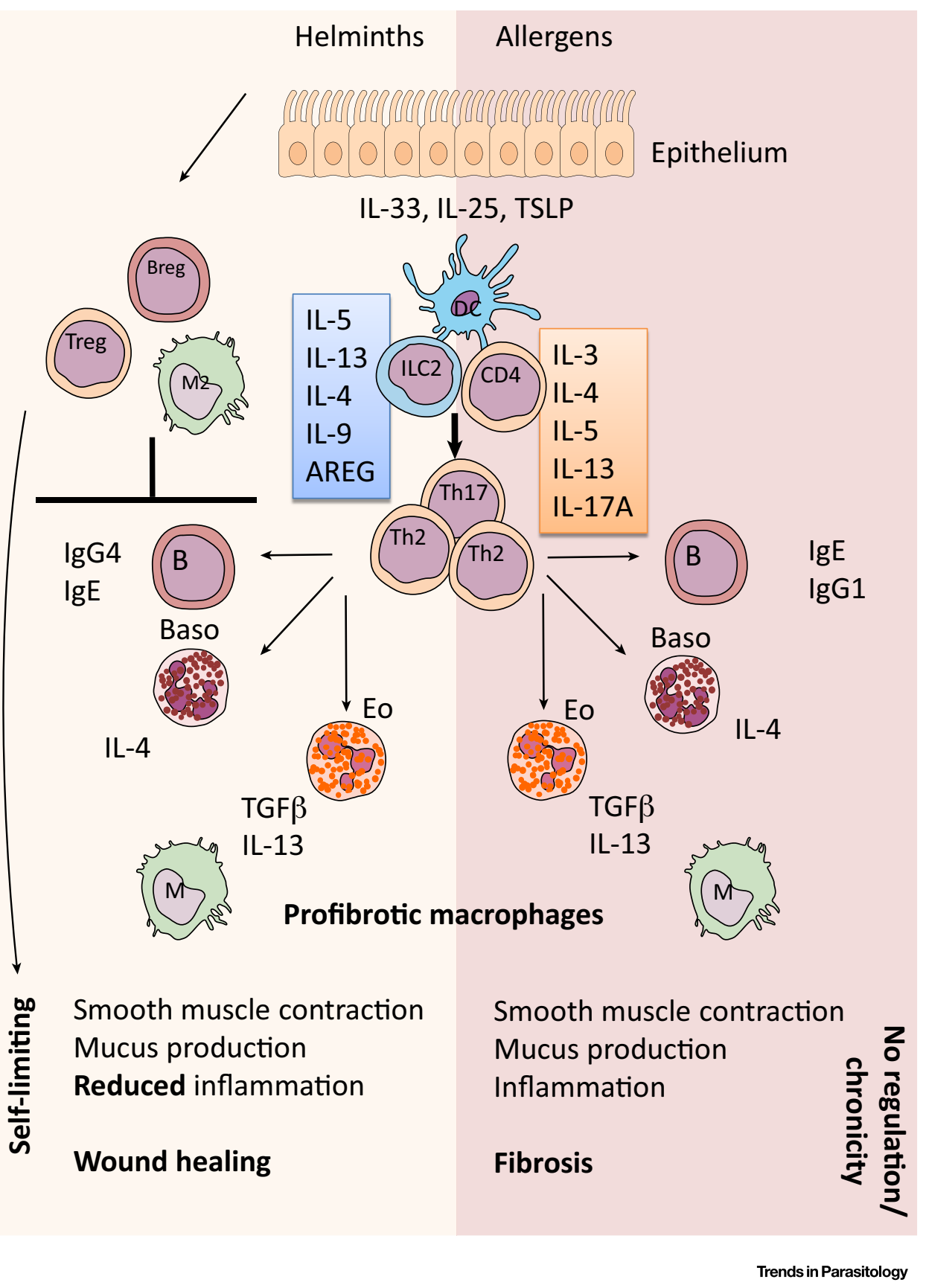

Figure 2. The Insult of Helminths and Allergens on Epithelial Cells. Both helminths and allergens evoke a strong type 2 immune response but while helminths induce immunoregulation, allergen encounters can result in uncontrolled chronic inflammation. Infection of the lung epithelium by helminths, or inhalation of allergens, trigger a cascade of cellular immune processes involving the crosstalk of dendritic cells (DCs), group 2 innate lymphoid cells (ILC2) and CD4 T cells to promote the release of type 2-associated cytokines (blue box: ILC2-derived; orange box: T cell-derived). Expansion of Th2 and Th17 cells promotes eosinophilia, basophilia, and class switching to type 2-associated antibody isotypes in B cells (IgE, IgG1, IgG4). Basophils (Baso) enhance Th2 polarisation through the release of IL-4, eosinophils release TGF $\beta$ and IL13. This cascade culminates in the activation of profibrotic macrophages, smooth muscle contraction, and mucus production. During helminth infection, regulatory cells (Treg, Breg, M2 macrophages) are induced via migration-induced damage and helminth-derived immunomodulatory molecules. Immunoregulation leads to the preferential switch to 


\section{Trends in Parasitology}

Helminth Migration Promotes an Anti-inflammatory Environment in the Lung In the context of helminth infection, epithelial-derived alarmins, such as IL-25 and IL-33, are released, which mainly act on ILC2s, but also macrophages, dendritic cells (DCs), mast cells, basophils, and CD4 T cells to promote the expression of type 2 cytokines, such as IL-4 and IL13. During the initial damage response, $I L-4 R \alpha$ signalling in macrophages is required to suppress haemorrhaging and neutrophil influx, the main contributors to pathology during N. brasiliensis infection [37]. IL-4-induced expression of insulin-like growth factor 1 (IGF-1) and Arg-1 in M2 macrophages promotes repair during $N$. brasiliensis infection of mice [37]. IGF-1 can act on nonprofessional phagocytes, such as epithelial cells, to preferentially engulf microvesicles, which dampens the epithelial inflammatory response [38]. Furthermore, suppression of T cells in order to prevent inflammation (beneficial for the host) and premature larval retention (beneficial for the parasite) can be achieved by Arg-1-mediated depletion of free I-arginine and direct suppression via inhibitory receptor PD-L2 expressed by M2 macrophages [39,40].

Control of Th2 responses involves regulatory networks, including IL-10, TGF- $\beta$, and natural and induced Tregs. IL-10 especially has been associated with the control of asthmatic responses, with $T$ cells from allergic individuals predominantly producing $\mathrm{IL}-4$ compared to their nonallergic counterparts, which produce more IL-10 [41]. Importantly, IL-10, together with IL-4 and IL-13, are important in promoting alternative activation of macrophages during helminth infection [37]. A recent study suggested that, in addition to Tregs, ILC2s are capable of producing IL-10; however, the physiological relevance of this phenomenon remains unclear [42].

The cytokine IL-9 is associated with wound healing responses during nematode infection [43]. IL-9 is required for autocrine amplification of ILC2 function and to promote tissue restoration, in part mediated by the production of AREG. IL-33 and thymic stromal lymphopoietin (TSLP) synergistically activate interferon regulatory factor 4 and IL-9 in ILC2s to increase IL-5 and IL-13 production to maintain epithelial cell homeostasis [44].

The epidermal growth factor receptor (EGFR) ligand AREG is associated with wound repair in the gut [45] and lung [43] and can be produced by CD4 T cells, mast cells, and ILC2 [46]. AREG is essential for the optimal function of Treg cells and damage repair during hookworm infection. Recently, it was shown that EGFR - in response to AREG-mediated activation - forms a complex with IL-1 receptor family member ST2 to allow for IL-33-mediated IL-13 expression, and mice with EGFR-deficient T cells showed impaired resistance to hookworm infections [47]. EGFR expression on Th2 cells was induced in an antigen-dependent manner, and the presence of a functional ST2-EGFR heterodimer renders Th2 cells responsive to IL-33, thereby promoting an innate-like response from previously antigen-licensed Th2 cells [45].

For humans in helminth-endemic areas, continuous exposure and risk of repeat infections raise the possibility that the recurring transmission of larvae may lead to increased or reduced pulmonary inflammation. Experimentally, daily low-dose (trickle) infections could be used as a model to investigate the impact of such reinfections on lung inflammation.

Most helminth infections induce anti-inflammatory macrophages and regulatory $T$ cells, and the expression of IL-10, TGF- $\beta$, IL-9, and AREG, which have important roles in the control of lung

blocking IgG4 antibodies, whereas allergens promote proinflammatory isotypes, such as IgG1. In the end, helminthinduced pulmonary inflammation results in self-limiting wound repair, while unregulated tissue damage and fibrosis develops in response to allergens. Abbreviations: IL, interleukin; TSLP, thymic stromal lymphopoietin; ILC2, group 2 innate lymphoid cells; Th, T helper; AREG, amphiregulin; Breg, regulatory B cell; Treg, regulatory T cell; Baso, basophil granulocyte; Eo, eosinophil granulocyte; TGF $\beta$, transforming growth factor $\beta$. 


\section{Trends in Parasitology}

repair. These regulatory pathways can either be activated intrinsically or enforced by helminth products, which - as a side effect - also limit inflammation.

\section{Helminth Immunomodulatory Molecules Enforce Anti-inflammatory Responses}

Associations between the increased prevalence of asthma in developing countries undergoing parasite-elimination programs has led to interest in using helminths to treat asthma [48]. A 2014 longitudinal study showed decreased asthma morbidity in endemic areas of Brazil [49]. However, ascariasis has been shown to be strongly associated with the development of asthma in rural China [50] and indeed, infection with Ascaris suum is used as a model of asthma in nonhuman primates [51]. Unsuccessful trials in using whipworms in the treatment of inflammatory bowel disease, inconclusive results in a meta-analysis of efficacy of helminth treatment [52], and positive association between Ascaris and asthma [53], as well as the paucity of in-depth knowledge on helminth immunobiology [54], calls for caution in assessing the efficacy of iatrogenic helminth therapies [55]. Administration of Trichuris suis ova (TSO) the pig whipworm - is the most prominent example in which live helminths have been used to treat illness, inflammatory bowel diseases in this case [56]. However, TSO failed to treat allergic rhinitis [57]; TSO infection is self-limiting and clears within a few weeks, which raises the question as to whether TSO robustly induces a long-lasting anti-inflammatory environment or whether the lack thereof caused the trials to fail. A small cohort trial using the human hookworm N. americanus to treat asthma showed a small improvement in airway function [58]. However, more extensive studies are required - especially in the light of promising results using $N$. americanus to treat celiac disease during which immunoregulation was established [59].

Numerous studies - including those using mouse models of asthma - have found a beneficial effect of helminth products on pulmonary allergic responses, either during initial sensitisation or during the effector phase of the response. Helminths excrete and secrete a plethora of immunomodulatory molecules that act in a range of inflammatory processes and have potential as novel anti-inflammatory compounds [57]. Administration of ES-antigen preparations from several helminths during allergen sensitisation suppresses the development of allergic inflammation $[60,61]$. A common theme is the modulation of the Th2 response towards a Th2 plus Treg-like response (the so-called modified Th2 response) [62]. Other helminth ES proteins are also capable of inhibiting an established Th2 response when administered during the challenge phase [61]. Nippostrongylus ES products elicit a Th2 response by modulating DC function, while suppressing proinflammatory Th1 responses through inhibition of IL-12p70 release from DCs [63].

We will not address the spectrum of helminth immunomodulatory molecules that can modulate immunity in detail herein, as this has been reviewed previously $[54,64,65]$. We will now highlight recent advances on selected novel immunomodulatory molecules or modulatory mechanisms that have been shown to alter lung inflammation (Figure 3).

Filarial ES-62 and Av17

One of the most extensively investigated helminth immunomodulatory molecules is the secreted glycoprotein ES-62 from the filarial nematode Acanthocheilonema viteae. ES-62, due to phosphorylcholine moieties, has been shown to have potent modulatory effects in a range of animal models of inflammatory diseases [66]. In mouse models of allergen-induced sensitisation of the lungs, ES-62 has been shown to prevent the development of lung inflammation with the modulation of mast cells [67], as allergen-specific responses and alteration in the cytokines and downstream eosinophilia compromise lung functions $[66,68]$. 


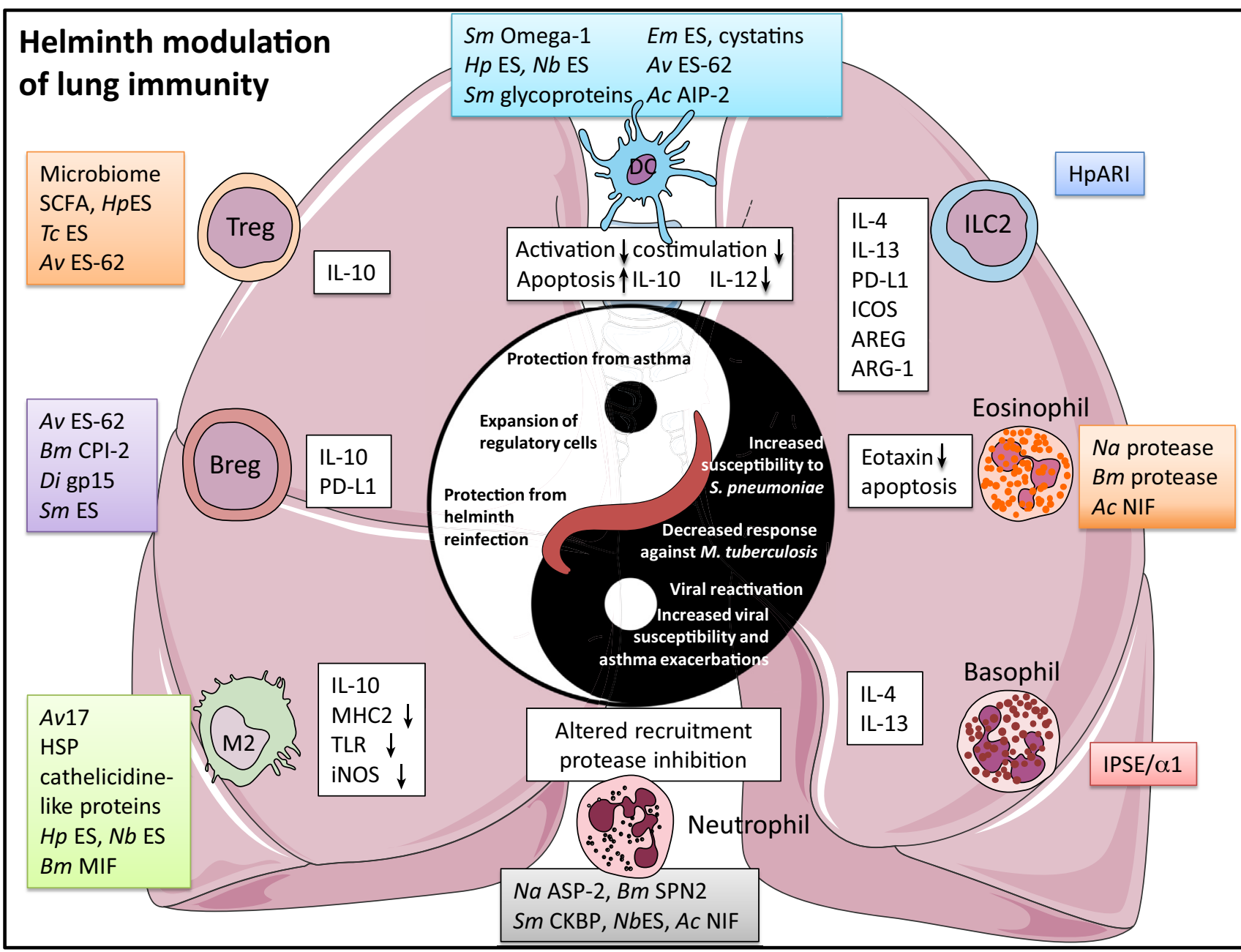

Trends in Parasitology

Figure 3. The Yin and Yang of Lung Immunity Modulation by Helminth Infection and Specific Helminth Immunomodulators That Alter Cellular Immune Processes. Helminth-derived immunomodulatory molecules (outer boxes) target different cell populations and modulate the release of their mediators (inner boxes) that affect type 2 immune responses. Schistosoma mansoni (Sm) Omega-1 and other glycoproteins, excretory/secretory (ES) products of Heligmosomoides polygyrus (Hp), Nippostrongylus brasiliensis (Nb) [63], Echinococcus multilocularis (Em) [115], and Acanthocheilonema viteae (Av), as well as Av-derived ES-62 and AIP2 of Ancylostoma caninum (Ac) impair maturation (decreased activation and costimulation) and Th1-inducing capabilities (reduced IL-12 release and production of IL10) of dendritic cells (DCs). Heligmosomoides polygyrus Alarmin Release Inhibitor (HpARI) inhibits the activation of ILC2, thereby reducing initial release of type 2 cytokines. ILC2 are activated through damage-induced alarmin-release to initiate and modulate pulmonary wound-healing responses via various proteins (IL-4, IL-13, amphiregulin [AREG], arginase-1 [ARG-1], programmed death receptor ligand 1 [PD-L1], inducible costimulator [ICOS]). Proteases of Brugia malayi (Bm) and Necator americanus (Na) [116], and the release of neutrophil inhibitory factor (NIF) from A. caninum [117] target eosinophil recruitment (eoatxin is cleaved) and survival (increased apoptosis). Schistosoma mansoni-derived IPSE/alpha-1 (interleukin-4-inducing principle from S. mansoni eggs) activates basophils via IgE to release IL-4 independently of antigen-specificity [118]. Neutrophil recruitment and inhibition of neutrophil proteases is targeted by N. americanus ASP-2 (Ancylostoma secreted protein-2) [119], B. malayi SPN-2 (serine protease inhibitor-2) [120], S. mansoni CKBP (chemokine-binding protein) [121], N. brasiliensis ES [122], and A. caninum NIF. Antigenpresentation and alternative activation of macrophages is impaired through $A$. viteae Av17, cathelicidine-like proteins [123], ES of N. brasiliensis and $H$. polygyrus, and B. malayi macrophage inhibitory factor (MIF) [124]. B cells are influenced by A. viteae ES-62, B. malayi CPI-2 [125], gp15 of Dirofilaria immitis (Di) [126], and S. mansoni ES. Regulatory T cells are induced though helminth-elicited changes in the host microbiome, including the increase of short-chain fatty acids (SCFA), $A$. viteae ES-62, as well as ES of $H$. polygyrus and Taenia crassiceps (Tc) [127]. This (nonexhaustive) list of immunomodulators acting on numerous host cell populations illustrates how helminth parasites are able to target different mechanisms in order to create an anti-inflammatory environment in the lung. Helminth infection is beneficial for the host by inducing protective immunity, establishing regulatory cells, and protecting from exaggerated airway inflammation. At the same time, pulmonary immune responses against (myco-)bacterial and viral pathogens relying on a proinflammatory Th1 response are impaired. 


\section{Trends in Parasitology}

A number of small-molecule analogues of ES-62 have been designed, with two small-molecule analogues (11a and 12b) that recapitulate the therapeutic actions of the parent helminth molecules [69] by targeting DCs [70]. In addition to ES-62, A. viteae expresses the cystatin Av17, which suppresses airway inflammation when administered at the sensitization stage or before challenge, in an IL-10- and macrophage-dependent manner [71].

\section{Schistosoma and B Regulatory Cells}

In mice, anaphylaxis is mechanistically prevented by $S$. mansoni infection through the induction of IL-10-producing B regulatory (Breg) cells [31]. Importantly, an expansion of Breg cells also occurs in Schistosoma-infected humans [72]. Recently, it was shown that schistosome egg antigens, including IPSE/alpha-1, can drive the expansion of Breg cells and inhibit airway inflammation [73,74]. Bregs induced with schistosome soluble egg antigens (SEA) were shown to mediate suppression of effector Th17 cells via Treg expansion, favouring the development of IL-4-expressing Th2 cells [75]. While Breg cells are the main immunomodulatory cells during schistosomiasis, cyclophilin A from SEA has recently been shown to drive Treg differentiation via DC modulation [76]. In conclusion, Schistosoma-derived products are inducers of a potent regulatory network that functions to suppress inflammation at distal sites, thereby protecting against airway inflammation. Similarly, Bregs induced during intestinal $H$. polygyrus infection suppressed lung pathology following allergen challenge independent of $B$ cell-derived IL-10 [77].

\section{Nematodes and Tregs}

In addition to Bregs, $H$. polygyrus potently induces Tregs with a TGF- $\beta$-like protein found to be responsible for expansion of Tregs [78]. Transfer of Tregs expanded in the presence of $H$. polygyrus-ES (HES) protected against allergen-induced pathology, whereas mammalian TGF$\beta$-derived Tregs were less effective [78]. Schistosoma-derived Omega-1 was also shown to induce Tregs in a TGF- $\beta$ - and retinoic acid-dependent manner [79]. Recently, anti-inflammatory protein-2 (AIP-2) was identified, which is a hookworm-secreted protein that suppresses airway inflammation in mice, reduces costimulatory markers on human DC, and suppresses $\mathrm{T}$ cell proliferation from allergic subjects. Suppression in mice was dependent on $\mathrm{CD}_{103^{+}} \mathrm{DCs}$ originating in the mesenteric lymph nodes capturing AIP-2, inducing forkhead box P3 (FoxP3) ${ }^{+}$ Tregs, and thereby promoting immunosuppression at distant mucosal sites [80].

\section{H. polygyrus-mediated IL-33 Inhibition}

A novel mechanism of inhibiting pulmonary innate immune responses has recently been published [81]. The H. polygyrus-derived Alarmin Release Inhibitor (HpARI) binds IL-33 and thereby prevents the activation of ILC2s. Recombinant HpARI administered to N. brasiliensisinfected mice inhibited eosinophilia in the lungs and prevented eosinophilic inflammation in a model of asthma using Alternaria allergen administration [73].

Recent progress made in identifying single helminth-derived immunomodulatory molecules highlights their potency to enforce an anti-inflammatory environment without the need for a naturally occurring anti-inflammatory wound-healing response. It is tempting to speculate that these evolved to ensure the parasites' survival in a host already primed for an antiviral or antibacterial Th1-biased response within the lung.

The Helminth-Induced Anti-inflammatory Environment Influences Pulmonary Bacterial and Viral Coinfections

Coinfections of helminths and Mycobacterium tuberculosis are certainly among the most clinically relevant coinfections worldwide. Protective immunity against $M$. tuberculosis infection 


\section{Trends in Parasitology}

is dependent on a strong Th1 response, and most $M$. tuberculosis-infected people remain latently infected and asymptomatic; however, they run a 10\% lifetime risk of reactivation of the disease [82]. The direct influence of helminth infection on activation of tuberculosis is not completely understood. Studies on $M$. tuberculosis and helminth coinfections showed decreased protection against $M$. tuberculosis conferred by bacille Calmette-Guérin (BCG) vaccination in individuals coinfected with helminths [83], and experimentally coinfected animals have an impaired BCG-specific Th1 response [84]. Recently, it was shown that $M$. tuberculosisinfected mice coinfected with S. mansoni or injected with SEA, in addition to impaired Th1 responses, accumulated Arg-1-expressing macrophages in the lung, leading to exacerbated disease severity and inflammation - all of which were reversed by anthelmintic treatment [85]. However, no association between gastrointestinal parasite or filarial nematode infection and progression to active tuberculosis was found in HIV-positive populations in Brazil and Uganda $[86,87]$. Further, a longitudinal study conducted in Southern India found no significant difference in progression from latent to active tuberculosis (or severity thereof) between individuals who were infected with helminths at the beginning of the study and uninfected individuals [88].

Mice infected with the helminth Taenia crassiceps or $H$. polygyrus developed more severe pneumonia upon infection with Streptococcus pneumoniae, but not with influenza or Staphylococcus aureus infection [89], although further studies are required to explain the observation. When mice are coinfected with H. polygyrus and Bordetella bronchiseptica, both infections are altered: bacterial burdens are higher, leading to increased host mortality, and animals exhibit higher worm burdens and therefore shed more parasite eggs [90].

Studies investigating helminth coinfections during viral infections have found that helminths and their products create an environment favouring the helminth while shutting down antiviral immunity, which is particularly important in the context of HIV infection and treatment, as anthelmintic regimens increase the responsiveness to antiretroviral therapy [91]. With regard to pulmonary inflammation, it was shown that mice already infected with Trichinella spiralis [92] did not contain subclinical norovirus infection, a result that was independent of the intestinal microbiome and in part rescued by inactivation of the chitinase-like protein Ym1 of macrophages. In another study, mice were infected with dormant $\gamma$-herpesvirus or Kaposi's sarcomaassociated herpesvirus, which were reactivated when the mice were infected with $H$. polygyrus or S. mansoni [93]. Conversely, a recent study revealed that mice infected with $H$. polygyrus were partly protected from respiratory syncytial virus (RSV) infection, measured by reduced viral load and lung inflammation, a mechanism independent of the adaptive immune system and IL$4 \mathrm{R} \alpha$ [94]. H. polygyrus itself induced the pulmonary expression of interferon $\beta$, and interferonstimulated genes, and augmented its expression in response to RSV infection. Interestingly, $H$. polygyrus-induced protection from RSV was dependent on the presence of microbiota, as it was absent in germ-free or antibiotic-treated mice, but further mechanistic studies are required to understand the link in this particular model [94]. Recently, AvCystatin/Av17, a recombinant cysteine protease inhibitor derived from the filarial nematode $A$. viteae, was tested during experimental vaccine-enhanced RSV infection [81]. AvCystatin prevented Th2-mediated immunopathology by ablating eosinophil influx and preventing weight loss and neutrophil recruitment. Furthermore, AvCystatin protects from excessive inflammation during the primary immune response by reducing neutrophil recruitment. AvCystatin acting on macrophages induces an influx of IL-10+ Tregs into the lungs [95].

\section{The Allergic Response versus Helminth Infections}

The arms race between helminths and immunity is well described [96]. The immune system functions to protect humans, with inflammation - a protective host response against infections 


\section{Trends in Parasitology}

and sterile injury - used to repair and resolve cellular and tissue injury. In the steady state, the immune system creates a state of homeostasis that maintains a healthy life span. In the event of immune dysregulation, aberrant inflammation can initiate chronic pathologies, leading to a spectrum of inflammatory and autoimmune diseases. Indeed, inflammation is central to many common diseases, such as arthritis, inflammatory bowel disease (IBD), obesity, and cancer. In such human disorders a widely used approach is to address the causes - spanning genetics to environmental factors - of the extreme aberrant immune responses when overt inflammatory disease develops.

From an evolutionary perspective, arthritis, IBD, obesity, and especially cancer, whilst not 'benefiting' from a long-living host, certainly put some pressure on the development of mechanisms to cope with or prevent the development of these conditions. In contrast, in helminth infections, a dead host usually means that the parasites' life cycle comes to an end as well. Coevolution of parasite and host has led to a fine balance between immune suppression and immunity. As described, the pulmonary damage is generally limited and not life-threatening itself because the immune response is already primed for tissue protection and modulated by the parasite. In the end, compromising a proinflammatory response against the helminth decreases host fitness costs, and an equilibrium between the immune response and damage (both from the immune response and the parasite) is reached. Medzhitov and colleagues [83] developed this thesis and, while it is known that disease tolerance where an infection may present limited immunopathology may develop in humans, the underlying mechanisms are not fully elucidated. One explanation - the IgE blocking hypothesis - is based on the observation that, during helminth infections, more polyclonal lgE is produced and thereby the high-affinity receptors for lgE (Fc\&RI) on mast cells and basophils are saturated with low-affinity antibodies [97]. Therefore, basophils and mast cells, which otherwise would degranulate and release proallergic mediators - such as histamine, IL-4, IL-13, or prostaglandins - are not activated and thereby immediate allergic reactions are prevented. This hypothesis is still discussed as it has been found that suppression of basophil hyper-reactivity is dependent on host-derived IL-10, which also downregulates $\mathrm{IgE}$ production and thereby decreases the number of FcERI molecules on basophils [98-100]. Comparing histamine release from basophils before and after anthelmintic treatment showed basophil suppression during helminth infection [101], proposing that helminths suppress allergy through the inhibition of basophil responses. However, one antigen was identified in $\mathrm{N}$. brasiliensis-infected mice ( $\mathrm{Nb}-\mathrm{Ag} 1)$, which induced $\mathrm{Nb}$-Ag1-specific IgE and was able to bind to the pharyngeal region of the helminth [102]. Furthermore, specific IgE is present in the serum of infected mice, and Nb-Ag1-IgE can sensitize mast cells, and possibly basophils, to degranulate. Importantly, basophils sensitized by $\lg E$ raised during the first infection contribute to protection against a subsequent infection with the same helminth, arguing against the lgE-blocking hypothesis [102,103]. Because lgE is only generated late during the immune response against the first infection with helminths, and $\lg \mathrm{E}$ requires sequential switching from $\operatorname{lgG} 1^{+}$memory $\mathrm{B}$ cells, the lgE-blocking hypothesis should be investigated discriminating between first infections and subsequent challenge infections [104].

Another model to reconcile the differences between allergies and helminth infections is the modified Th2 response evoked by helminth parasites. While allergens induce a potent proallergic type 2 cytokine-driven immune response, the helminth-induced immune response is modified by a regulating quality [62]. In this modified Th2 response, downstream effects are muted and result, for example, in the increase of noncomplement fixing IgG4 and IL-10, instead of inflammation-promoting IgG1, IgE, and IL-5 [105]. Evidence for this hypothesis comes from studies in which children who are exposed to cat allergens have reduced asthma levels. The 


\section{Trends in Parasitology}

decrease in Th2 responses is cat allergen-specific, as house dust mites do not confer a similar protection. The study found that high-level exposure to cat allergens induces IgG4 antibodies, which counteract allergen-specific IgE responses, and leads to increased IL-10 in exposed individuals and in in vitro cat-allergen-stimulated T cells [106]. Similarly, beekeepers who are constantly exposed to the major bee venom allergen phospholipase A2 show elevated IgG4isotype-switched antibodies, which are produced by IL-10-producing Bregs [107]. Consequently, allergen-specific immunotherapy aiming to desensitize allergic patients by inducing allergen-specific Tregs show preferential switching of allergen-specific B cells from IgE towards the blocking IgG4 isotype [108]. Interestingly, in schistosome-infected mice, IL-10-producing Bregs that suppress allergic lung inflammation via Tregs are also elicited [24].

Schistosoma-infected asthma patients show an increase in pulmonary IL-10 [109]. Experimental data from Schistosoma-infected mice suggests that a compartmentalized modification by the schistosomes occurs specifically in the lung. These mice are refractory to ovalbumin (OVA)-induced airway inflammation, while systemic OVA-induced responses remain intact [110]. A possible explanation for this phenomenon lies within the parasite's life cycle. Exposed infected individuals constantly encounter Schistosoma cercariae. Because the worm cannot afford its host to die of hyper-parasitemia, it has evolved a mechanism preventing this: concomitant immunity. Brought forward almost 50 years ago [111], concomitant immunity is a state in which the adult worms vaccinate their host with larval antigens, rendering the host immune to reinfections, thereby trapping newly invading larvae within the lung, while allowing the adult worm to survive. In order to control the pulmonary inflammation occurring in response to dead larvae in the lung, the aforementioned regulatory mechanisms prevent overwhelming immune responses with beneficial (allergies) and detrimental (viral and bacterial infections) side effects.

\section{Concluding Remarks}

Helminths have coevolved excellent strategies to deal with host immune responses, to limit direct and bystander tissue damage, while educating our immune system to tolerate infection. When helminth infections were common, the fitness advantage on our side was to tolerate the parasites. With increased sanitation, inhaled innocuous allergens trigger a similar response without the regulatory mechanisms triggered or provided by the presence of helminths. In particular, immune responses are heavily influenced by helminths passing through the lung or through their release of immunomodulators. Importantly, these potent immunomodulators are able to influence pulmonary immune responses with adult helminths dwelling at distal sites. Treatment with live helminths, although theoretically the most potent approach in terms of inducing a regulatory response, is not feasible because of the uncontrollable risk of the unknown unknowns - succumbing to infection, reactivating viruses, adverse side effects, and promoting unrelated malignancies (see Outstanding Questions). Identification of the active ingredient in the complex mixtures of excreted and secreted substances would allow us to exploit this knowledge for novel therapeutic approaches. While it remains to be determined if helminths could be a source of new therapies for lung inflammatory diseases, it is clear that fundamental research on the immunobiology of helminth modulation of lung immunity will continue to deliver new insight into the processes that regulate pulmonary function in health and disease.

\section{Outstanding Questions}

How do we therapeutically convert the allergic Th2 response towards a helminth-modified Th2 response to reduce allergic lung inflammation? How can we use helminths to induce regulatory cells in allergic individuals without compromising immunity towards viruses and bacteria?

How do helminth-induced changes to the host microbiome influence systemic and pulmonary immune responses?

As Trichuris suis trials failed in the treatment of human asthma, is Necator americanus a suitable alternative or will a single helminth molecule be more successful?

If helminth products are recombinantly manufactured, are they effective and safe to use?

Can current recombinant engineering produce a helminth molecule, including all its naturally occurring modifications introduced by millions of years of evolutionary fine-tuning? If they are not mimicking the natural helminth product will it work in humans?

Most experimental animal models use acute, high-dose infections - what can we learn from continuous low-dose (trickle) infections resembling exposure in endemic areas?

Human helminth infection occurs in males and females, while experimental infection of animals often is done in only one sex. As new studies arise on the influence of sex hormones on innate immunity, what are the consequences for wound healing and protective immunity?

Host age impairs wound healing responses - how does this translate to helminth resistance, and could helminth immunomodulators improve wound healing in older patients?

\section{Acknowledgments}

PGF was supported by Science Foundation Ireland (10/IN.1/B3004), the Wellcome Trust (092530/Z/10/Z), and National Children's Research Centre. CS is a Long-Term EMBO Fellow (ALTF 587-2016). EH is a Science Foundation Ireland SIRG award holder (15/SIRG/3473). 
Trends in Parasitology

\section{References}

1. Craig, J.M. and Scott, A.L. (2014) Helminths in the lungs. Parasite Immunol. 36, 463-474

2. Neill, D.R. et al. (2010) Nuocytes represent a new innate effector leukocyte that mediates type- 2 immunity. Nature 464, 13671370

3. Price, A.E. et al. (2010) Systemically dispersed innate IL-13expressing cells in type 2 immunity. Proc. Natl. Acad. Sci. U. S. A. $107,11489-11494$

4. Moro, K. et al. (2010) Innate production of $\mathrm{T}(\mathrm{H}) 2$ cytokines by adipose tissue-associated c-Kit(+)Sca-1(+) lymphoid cells. Nature 463, 540-544

5. Cardoso, V. et al. (2017) Neuronal regulation of type 2 innate lymphoid cells via neuromedin U. Nature 549, 277-281

6. Klose, C.S.N. et al. (2017) The neuropeptide neuromedin $U$ stimulates innate lymphoid cells and type 2 inflammation. Nature 549, 282-286

7. Wallrapp, A. et al. (2017) The neuropeptide NMU amplifies ILC2driven allergic lung inflammation. Nature 549, 351-356

8. von Moltke, J. et al. (2016) Tuft-cell-derived IL-25 regulates an intestinal ILC2-epithelial response circuit. Nature 529, 221-225

9. Gerbe, F. et al. (2016) Intestinal epithelial tuft cells initiate type 2 mucosal immunity to helminth parasites. Nature 529, 226-230

10. Howitt, M.R. et al. (2016) Tuft cells, taste-chemosensory cells, orchestrate parasite type 2 immunity in the gut. Science 351 , 1329-1333

11. Gerbe, F. et al. (2012) The intestinal epithelium tuft cells: specification and function. Cell. Mol. Life Sci. 69, 2907-2917

12. Chen, F. et al. (2014) Neutrophils prime a long-lived effector macrophage phenotype that mediates accelerated helminth expulsion. Nat. Immunol. 15, 938-946

13. Sutherland, T.E. et al. (2014) Chitinase-like proteins promote IL17-mediated neutrophilia in a tradeoff between nematode killing and host damage. Nat. Immunol. 15, 1116-1125

14. Reece, J.J. et al. (2008) Hookworm-induced persistent changes to the immunological environment of the lung. Infect. Immun. 76, 3511-3524

15. Panzer, M. et al. (2012) Rapid in vivo conversion of effector $T$ cells into Th2 cells during helminth infection. J. Immunol. 188, 615-623

16. Gagliani, N. et al. (2015) Th17 cells transdifferentiate into regulatory T cells during resolution of inflammation. Nature 523, 221225

17. Harvie, M. et al. (2010) The lung is an important site for priming CD4 T-cell-mediated protective immunity against gastrointestinal helminth parasites. Infect. Immun. 78, 3753-3762

18. Hams, E. et al. (2013) The schistosoma granuloma: friend or foe? Front. Immunol. 4, 89

19. MacDonald, A.S. et al. (2002) Impaired Th2 development and increased mortality during Schistosoma mansoni infection in the absence of CD40/CD154 interaction. J. Immunol. 168, 46434649

20. Fallon, P.G. et al. (2000) Elevated type 1, diminished type 2 cytokines and impaired antibody response are associated with hepatotoxicity and mortalities during Schistosoma mansoni infection of CD4-depleted mice. Eur. J. Immunol. 30, 470-480

21. Schwartz, C. et al. (2014) T cell-derived IL-4/L-13 protects mice against fatal Schistosoma mansoni infection independently of basophils. J. Immunol. 193, 3590-3599

22. Fallon, P.G. et al. (2002) IL-4 induces characteristic Th2 responses even in the combined absence of IL-5, IL-9, and IL-13. Immunity 17, 7-17

23. Urban, J.F., Jr et al. (1998) IL-13, IL-4Ralpha, and Stat6 are required for the expulsion of the gastrointestinal nematode parasite Nippostrongylus brasiliensis. Immunity 8 , 255-264
24. Amu, S. et al. (2010) Regulatory B cells prevent and reverse allergic airway inflammation via FoxP3-positive T regulatory cells in a murine model. J. Allergy Clin. Immunol. 125, 1114-1124 e8

25. van der Vlugt, L.E. et al. (2012) Schistosomes induce regulatory features in human and mouse CD1d(hi) B cells: inhibition of allergic inflammation by $\mathrm{L}-10$ and regulatory $T$ cells. PLOS One 7, e30883

26. Schroeder, J.H. et al. (2017) Brugia malayi microfilariae adhere to human vascular endothelial cells in a C3-dependent manner. PLoS Negl. Trop. Dis. 11, e0005592

27. Cadman, E.T. et al. (2014) Eosinophils are important for protection, immunoregulation and pathology during infection with nematode microfilariae. PLoS Pathog. 10, e1003988

28. Finney, C.A. et al. (2007) Expansion and activation of CD4(+ CD25(+) regulatory T cells in Heligmosomoides polygyrus infection. Eur. J. Immunol. 37, 1874-1886

29. Zaiss, M.M. et al. (2015) The intestinal microbiota contributes to the ability of helminths to modulate allergic inflammation. Immu nity 43, 998-1010

30. Kay, G.L. et al. (2015) Differences in the faecal microbiome in Schistosoma haematobium infected children vs. uninfected children. PLoS Negl. Trop. Dis. 9, e0003861

31. Mangan, N.E. et al. (2004) Helminth infection protects mice from anaphylaxis via IL-10-producing B cells. J. Immunol. 173, 63466356

32. Dewals, B. et al. (2010) Control of Schistosoma mansoni egg induced inflammation by IL-4-responsive CD4(+)CD25(CD103(+)Foxp3(-) cells is IL-10-dependent. Eur. J. Immunol. $40,2837-2847$

33. Smith, P. et al. (2004) Schistosoma mansoni worms induce anergy of $\mathrm{T}$ cells via selective up-regulation of programmed death ligand 1 on macrophages. J. Immunol. 173, 1240-1248

34. Minutti, C.M. et al. (2017) Tissue-specific contribution of macrophages to wound healing. Semin. Cell Dev. Biol. 61, 3-11

35. Eming, S.A. et al. (2014) Wound repair and regeneration: mechanisms, signaling, and translation. Sci. Transl. Med. 6, 265sr6

36. Herold, S. et al. (2011) Acute lung injury: how macrophages orchestrate resolution of inflammation and tissue repair. Front. Immunol. 2, 65

37. Chen, F. et al. (2012) An essential role for TH2-type responses in limiting acute tissue damage during experimental helminth infection. Nat. Med. 18, 260-266

38. Han, C.Z. et al. (2016) Macrophages redirect phagocytosis by non-professional phagocytes and influence inflammation. Nature 539, 570-574

39. Huber, S. et al. (2010) Alternatively activated macrophages inhibit T-cell proliferation by Stat6-dependent expression of PD-L2. Blood 116, 3311-3320

40. Pesce, J.T. et al. (2009) Arginase-1-expressing macrophages suppress Th2 cytokine-driven inflammation and fibrosis. PLOS Pathog. 5, e1000371

41. Akdis, M. et al. (2004) Immune responses in healthy and allergic individuals are characterized by a fine balance between allergenspecific T regulatory 1 and T helper 2 cells. J. Exp. Med. 199, 1567-1575

42. Wang, S. et al. (2017) Regulatory innate lymphoid cells contro innate intestinal inflammation. Cell 171, 201-216 e18

43. Turner, J.E. et al. (2013) IL-9-mediated survival of type 2 innate lymphoid cells promotes damage control in helminth-induced lung inflammation. J. Exp. Med. 210, 2951-2965

44. Mohapatra, A. et al. (2016) Group 2 innate lymphoid cells utilize the IRF4-IL-9 module to coordinate epithelial cell maintenance of lung homeostasis. Mucosal Immunol. 9, 275-286

45. Zaiss, D.M. et al. (2006) Amphiregulin, a TH2 cytokine enhancing resistance to nematodes. Science 314, 1746 


\section{Trends in Parasitology}

46. Zaiss, D.M. et al. (2013) Amphiregulin enhances regulatory T cell-suppressive function via the epidermal growth factor receptor. Immunity 38, 275-284

47. Minutti, C.M. et al. (2017) Epidermal growth factor receptor expression licenses type-2 helper T cells to function in a T cell receptor-independent fashion. Immunity 47, 710-722 e6

48. Wong, G.W. et al. (2006) Environmental determinants associated with the development of asthma in childhood. Int. J. Tuberc. Lung Dis. 10, 242-251

49. Ponte, E.V. et al. (2014) Reduced asthma morbidity in endemic areas for helminth infections: a longitudinal ecological study in Brazil. J. Asthma 51, 1022-1027

50. Palmer, L.J. et al. (2002) Ascaris lumbricoides infection is associated with increased risk of childhood asthma and atopy in rural China. Am. J. Respir. Crit. Care Med. 165, 1489-1493

51. Weiszer, I. et al. (1968) Ascaris hypersensitivity in the rhesus monkey. I. A model for the study of immediate type thypersensitity in the primate. J. Allergy 41, 14-22

52. Garg, S.K. et al. (2014) Helminth therapy (worms) for induction of remission in inflammatory bowel disease. Cochrane Database Syst. Rev. 2014, CD009400

53. Webb, E.L. et al. (2016) Helminths are positively associated with atopy and wheeze in Ugandan fishing communities: results from a cross-sectional survey. Allergy 71, 1156-1169

54. Khan, A.R. and Fallon, P.G. (2013) Helminth therapies: translating the unknown unknowns to known knowns. Int. J. Parasitol. 43, 293-299

55. Briggs, N. et al. (2016) The hygiene hypothesis and its inconvenient truths about helminth infections. PLoS Negl. Trop. Dis. 10, e0004944

56. Weinstock, J.V. and Elliott, D.E. (2013) Translatability of helminth therapy in inflammatory bowel diseases. Int. J. Parasitol. 43, 245-251

57. Nascimento Santos, L. et al. (2017) Recombinant proteins of helminths with immunoregulatory properties and their possible therapeutic use. Acta Trop. 166 (Suppl. C), 202-211

58. Feary, J.R. et al. (2010) Experimental hookworm infection: a randomized placebo-controlled trial in asthma. Clin. Exp. Allergy 40, 299-306

59. Croese, J. et al. (2015) Experimental hookworm infection and gluten microchallenge promote tolerance in celiac disease. J. Allergy Clin. Immunol. 135, 508-516

60. Trujillo-Vargas, C.M. et al. (2007) Helminth-derived products inhibit the development of allergic responses in mice. Am. J. Respir. Crit. Care Med. 175, 336-344

61. McSorley, H.J. et al. (2012) Suppression of type 2 immunity and allergic airway inflammation by secreted products of the helminth Heligmosomoides polygyrus. Eur. J. Immunol. 42, 26672682

62. Fallon, P.G. and Mangan, N.E. (2007) Suppression of TH2-type allergic reactions by helminth infection. Nat. Rev. Immunol. 7 , 220-230

63. Balic, A. et al. (2004) Selective maturation of dendritic cells by Nippostrongylus brasiliensis-secreted proteins drives Th2 immune responses. Eur. J. Immunol. 34, 3047-3059

64. Maizels, R.M. and McSorley, H.J. (2016) Regulation of the host immune system by helminth parasites. J. Allergy Clin. Immunol. 138, 666-675

65. Harnett, M.M. and Harnett, W. (2017) Can parasitic worms cure the modern world's ills? Trends Parasitol. 33, 694-705

66. Pineda, M.A. et al. (2014) ES-62, a therapeutic anti-inflammatory agent evolved by the filarial nematode Acanthocheilonema viteae. Mol. Biochem. Parasitol. 194, 1-8

67. Melendez, A.J. et al. (2007) Inhibition of Fc epsilon RI-mediated mast cell responses by ES-62, a product of parasitic filarial nematodes. Nat. Med. 13, 1375-1381

68. Rzepecka, J. etal. (2013) The helminth product, ES-62, protects against airway inflammation by resetting the Th cell phenotype. Int. J. Parasitol. 43, 211-223
69. Coltherd, J.C. et al. (2016) The parasitic worm-derived immunomodulator. ES-62 and its drug-like small molecule analogues exhibit therapeutic potential in a model of chronic asthma. Sci. Rep. 6, 19224

70. Lumb, F.E. et al. (2017) Dendritic cells provide a therapeutic target for synthetic small molecule analogues of the parasitic worm product, ES-62. Sci. Rep. 7, 1704

71. Schnoeller, C. et al. (2008) A helminth immunomodulato reduces allergic and inflammatory responses by induction of IL-10-producing macrophages. J. Immunol. 180, 4265-4272

72. Smits, H.H. et al. (2007) Protective effect of Schistosoma mansoni infection on allergic airway inflammation depends on the intensity and chronicity of infection. J. Allergy Clin. Immunol. 120, 932-940

73. Haeberlein, S. et al. (2017) Schistosome egg antigens, including the glycoprotein IPSE/alpha-1, trigger the development of regulatory B cells. PLoS Pathog. 13, e1006539

74. van der Vlugt, L. et al. (2017) Schistosome-induced pulmonary B cells inhibit allergic airway inflammation and display a reduced Th2-driving function. Int. J. Parasitol. 47, 545-554

75. Tian, F. et al. (2015) B10 cells induced by Schistosoma japo nicum soluble egg antigens modulated regulatory $T$ cells and cytokine production of T cells. Parasitol. Res. 114, 3827-3834

76. Floudas, A. et al. (2017) Composition of the Schistosoma mansoni worm secretome: Identification of immune modulaton Cyclophilin A. PLoS Negl. Trop. Dis. 11, e0006012

77. Wilson, M.S. et al. (2010) Helminth-induced CD19 + CD23hi B cells modulate experimental allergic and autoimmune inflammation. Eur. J. Immunol. 40, 1682-1696

78. Grainger, J.R. etal. (2010) Helminth secretions induce de novo cell Foxp3 expression and regulatory function through the TGFbeta pathway. J. Exp. Med. 207, 2331-2341

79. Zaccone, P. et al. (2011) The S. mansoni glycoprotein omegainduces Foxp3 expression in NOD mouse CD4(+) T cells. Eur. $J$. Immunol. 41, 2709-2718

80. Navarro, S. et al. (2016) Hookworm recombinant protein promotes regulatory $\mathrm{T}$ cell responses that suppress experimenta asthma. Sci. Transl. Med. 8, 362ra143

81. Osbourn, M. et al. (2017) HpARI protein secreted by a helminth parasite suppresses interleukin-33. Immunity 47, 739-751 e5

82. Vynnycky, E. and Fine, P.E. (2000) Lifetime risks, incubation period, and serial interval of tuberculosis. Am. J. Epidemiol. 152 $247-263$

83. Elias, D. et al. (2005) Schistosoma mansoni infection reduces the protective efficacy of BCG vaccination against virulent Mycobacterium tuberculosis. Vaccine 23, 1326-1334

84. Flias, D et al (2005) Low dose chronic Schistosoma mansoni infection increases susceptibility to Mycobacterium bovis BCG infection in mice. Clin. Exp. Immunol. 139, 398-404

85. Monin, L. et al. (2015) Helminth-induced arginase-1 exacerbates lung inflammation and disease severity in tuberculosis. J. Clin. Invest. 125, 4699-4713

86. Neto, L.M. et al. (2009) Enteroparasitosis prevalence and parasitism influence in clinical outcomes of tuberculosis patients with or without HIV co-infection in a reference hospital in Rio de Janeiro (2000-2006). Braz. J. Infect. Dis. 13, 427-432

87. Brown, M. et al. (2006) Schistosoma mansoni, nematode infections, and progression to active tuberculosis among HIV-1 infected Ugandans. Am. J. Trop. Med. Hyg. 74, 819-825

88. Chatterjee, S. et al. (2014) Incidence of active pulmonary tuberculosis in patients with coincident filarial and/or intestinal helminth infections followed longitudinally in South India. PLoS One 9, e94603

89. Apiwattanakul, N. et al. (2014) Helminth infections predispose mice to pneumococcal pneumonia but not to other pneumonic pathogens. Med. Microbiol. Immunol. 203, 357-364

90. Lass, S. et al. (2013) Generating super-shedders: co-infection increases bacterial load and egg production of a gastrointestina helminth. J. R. Soc. Interface 10, 20120588 


\section{Trends in Parasitology}

91. Ivan, E. et al. (2015) Effect of deworming on disease progression markers in HIV-1-infected pregnant women on antiretroviral therapy: a longitudinal observational study from Rwanda. Clin. Infect. Dis. 60, 135-142

92. Osborne, L.C. et al. (2014) Coinfection. Virus-helminth coinfection reveals a microbiota-independent mechanism of immunomodulation. Science 345, 578-582

93. Reese, T.A. et al. (2014) Helminth infection reactivates latent gamma-herpesvirus via cytokine competition at a viral promoter. Science 345, 573-577

94. McFarlane, A.J. et al. (2017) Enteric helminth-induced type I interferon signaling protects against pulmonary virus infection through interaction with the microbiota. J. Allergy Clin. Immunol. 140, 1068-1078 e6

95. Schuijs, M.J. et al. (2016) The helminth-derived immunomodulator AvCystatin reduces virus enhanced inflammation by induction of regulatory IL-10+ T cells. PLoS One 11, e0161885

96. Dunne, D.W. and Cooke, A. (2005) A worm's eye view of the immune system: consequences for evolution of human autoimmune disease. Nat. Rev. Immunol. 5, 420-426

97. Editorial (1976) IgE, parasites, and allergy. Lancet 1, 894-895

98. Larson, D. et al. (2012) Chronic helminth infection reduces basophil responsiveness in an IL-10-dependent manner. J. Immunol. 188, 4188-4199

99. Mitre, E. and Nutman, T.B. (2003) Lack of basophilia in human parasitic infections. Am. J. Trop. Med. Hyg. 69, 87-91

100. MacGlashan, D.W., Jr et al. (1997) Serum IgE level drives basophil and mast cell IgE receptor display. Int. Arch. Allergy Immunol. 113, 45-47

101. Larson, D. et al. (2012) Helminth infection is associated with decreased basophil responsiveness in human beings. J. Allergy Clin. Immunol. 130, 270-272

102. Pochanke, V. et al. (2007) Identification and characterization of a novel antigen from the nematode Nippostrongylus brasiliensis recognized by specific IgE. Eur. J. Immunol. 37, 1275-1284

103. Schwartz, C. et al. (2014) Basophil-mediated protection against gastrointestinal helminths requires lgE-induced cytokine secretion. Proc. Natl. Acad. Sci. U. S. A. 111, E5169-E5177

104. Turqueti-Neves, A. et al. (2015) The extracellular domains of IgG1 and T cell-derived IL-4/IL-13 are critical for the polyclonal memory lgE response in vivo. PLoS Biol. 13, e1002290

105. Adjobimey, T. and Hoerauf, A. (2010) Induction of immunoglobulin G4 in human filariasis: an indicator of immunoregulation. Ann. Trop. Med. Parasitol. 104, 455-464

106. Platts-Mills, T. et al. (2001) Sensitisation, asthma, and a modified Th2 response in children exposed to cat allergen: a populationbased cross-sectional study. Lancet 357, 752-756

107. van de Veen, W. et al. (2013) IgG4 production is confined to human IL-10-producing regulatory $B$ cells that suppress antigen-specific immune responses. J. Allergy Clin. Immunol. 131, 1204-1212

108. Jutel, M. et al. (2013) Mechanisms of allergen-specific immunotherapy and novel ways for vaccine development. Allergol. Int. 62, 425-433

109. Cardoso, L.S. et al. (2006) Schistosoma mansoni antigen-driven interleukin-10 production in infected asthmatic individuals. Mem. Inst. Oswaldo Cruz 101 (Suppl. 1), 339-343

110. Pacifico, L.G. et al. (2009) Schistosoma mansoni antigens modulate experimental allergic asthma in a murine model: a major role for CD4+ CD25+ Foxp3+ T cells independent of interleukin10. Infect. Immun. 77, 98-107

111. Smithers, S.R. and Terry, R.J. (1969) Immunity in schistosomiasis. Ann. N. Y. Acad. Sci. 160, 826-840

112. Maazi, H. et al. (2015) ICOS:ICOS-ligand interaction is required for type 2 innate lymphoid cell function, homeostasis, and induction of airway hyperreactivity. Immunity 42, 538-551

113. Oliphant, C.J. et al. (2014) MHCII-mediated dialog between group 2 innate lymphoid cells and CD4(+) T cells potentiates type 2 immunity and promotes parasitic helminth expulsion. Immunity 41, 283-295

114. Schwartz, C. et al. (2017) ILC2s regulate adaptive Th2 cell functions via PD-L1 checkpoint control. J. Exp. Med. 214 2507-2521

115. Nono, J.K. et al. (2012) Excretory/secretory-products of Echinococcus multilocularis larvae induce apoptosis and tolerogenic properties in dendritic cells in vitro. PLoS Negl. Trop. Dis. 6 , e1516

116. Culley, F.J. et al. (2000) Eotaxin is specifically cleaved by hookworm metalloproteases preventing its action in vitro and in vivo. J. Immunol. 165, 6447-6453

117. Schnyder-Candrian, S. et al. (2012) Neutrophil inhibitory facto selectively inhibits the endothelium-driven transmigration of eosinophils in vitro and airway eosinophilia in OVA-induced allergic lung inflammation. J. Allergy (Cairo) 2012, 245909

118. Schramm, G. et al. (2007) Cutting edge: IPSE/alpha-1, a glycoprotein from Schistosoma mansoni eggs, induces IgE-dependent, antigen-independent IL-4 production by murine basophils in vivo. J. Immunol. 178, 6023-6027

119. Bower, M.A. et al. (2008) Necator americanus: the Na-ASP-2 protein secreted by the infective larvae induces neutrophi recruitment in vivo and in vitro. Exp. Parasitol. 118, 569-575

120. Zang, X. et al. (1999) A novel serpin expressed by blood-borne microfilariae of the parasitic nematode Brugia malayi inhibits human neutrophil serine proteinases. Blood 94, 1418-1428

121. Smith, P. et al. (2005) Schistosoma mansoni secretes a chemokine binding protein with antiinflammatory activity. J. Exp. Med. 202, 1319-1325

122. Keir, P.A. et al. (2004) Inhibition of neutrophil recruitment by ES of Nippostrongylus brasiliensis. Parasite Immunol. 26, 137-139

123. Robinson, M.W. et al. (2012) A helminth cathelicidin-like protein suppresses antigen processing and presentation in macro phages via inhibition of lysosomal vATPase. FASEB J. 26, 4614-4627

124. Falcone, F.H. et al. (2001) A Brugia malayi homolog of macrophage migration inhibitory factor reveals an important link between macrophages and eosinophil recruitment during nematode infection. J. Immunol. 167, 5348-5354

125. Manoury, B. et al. (2001) Bm-CPI-2, a cystatin homolog secreted by the filarial parasite Brugia malayi, inhibits class I MHC-restricted antigen processing. Curr. Biol. 11, 447-451

126. Imai, S. et al. (2001) A factor of inducing IgE from a filaria parasite is an agonist of human CD40. J. Biol. Chem. 276, 46118-46124

127. Peon, A.N. et al. (2013) Immunoregulation by Taenia crassiceps and its antigens. BioMed Res. Int. 2013, 498583 